\title{
An application example for the new ICRP screening tool of JRodos
}

\author{
C. Landman ${ }^{1}$, W. Raskob ${ }^{1}$, D. Trybushnyi ${ }^{1}$ and I. Ievdin ${ }^{2}$ \\ 1 Karlsruhe Institute of Technology (KIT), Postfach 3640, 76021 Karlsruhe, Germany. \\ 2 Ukrainian Center for Environmental and Water Projects, prosp. Glushkova 42, 03187 Kiev, Ukraine.
}

\begin{abstract}
In 2012/2013 a screening tool that accounts for the new ICRP-103 recommendations was developed and implemented in the program environment of the JRodos system under the model name "ICRP". The article describes major features, results, and operational aspects of version 1.0 of this tool by means of an application example.
\end{abstract}

Keywords: ICRP screening tool / JRodos / NERIS-TP

\section{Introduction}

As part of the work performed in the framework of the project "Towards a self-sustained European Technology Platform (NERIS-TP) on Preparedness for Nuclear and Radiological Emergency Response and Recovery", a screening tool was developed (Landman et al., 2013) that accounts for the new ICRP-103 recommendations (ICRP, 2007); it was implemented in the program environment of the decision support system JRodos (Ievdin et al., 2010) under the model name "ICRP" as version ICRP 1.0.

The ICRP-103 concept proposes a "reference level" for emergency and existing controllable exposure situations that represents the level of the dose or risk above which it is judged to be inappropriate to allow planned exposure to occur, and introduces the concept of the "residual dose", which is the effective equivalent dose received from all exposure pathways over a certain time period, typically one year. Planning in advance will guarantee that for residents in the affected area the residual dose does not exceed the reference level. Such an approach requires an integrated treatment of all actions and exposure pathways in accidental and existing exposure situations that was not possible with the models existing so far.

In this context, the JRodos screening tool identifies one particular "action strategy" that brings the residual dose below the reference level, by considering the combined effect of actions under the one constraint of keeping a criterion dose below a given numerical value; current national intervention levels are not taken into account in the procedure. The use of the term "criterion dose" in this article rather than "residual dose" reflects the fact that a general consensus on details for calculating this quantity is missing. For ambiguous cases, ICRP 1.0 offers to select between variants to satisfy different functions.

\section{Input for the ICRP 1.0 model}

Among others, the screening tool makes use of results calculated with one of the JRodos atmospheric dispersion and deposition models of the near-range local-scale model chain. Therefore, on start-up, a successfully terminated calculation of this type has to be selected. After that, an interface opens which collects all user input and is implemented as four tabular sheets or "tabs"; see the top of Figures 1 and 2. Default settings allow starting without modifications; in such cases, all exposure pathways excluding ingestion of foodstuffs are considered.

One of the tabs (General parameters) serves for specifying the value for the reference level and for selecting whether noningestion doses will be calculated with the assumption of open air or normal living exposure; a mixture of open air exposure for the short term and normal living exposure for the longer term is currently not foreseen.

Another tab (Sheltering, absence from area, iodine prophylaxis) covers non-ingestion options and parameters. For instance, the user can select whether or not sheltering or thyroid blocking will be considered as a means of reducing doses. Another important item is the possibility to specify starting times for the testing of the efficiency of actions by graphically creating various timing zones on the JRodos grid and assigning different times to them. These "action sequence starting times" can be used to optimise the beginning of sheltering (if considered) with respect to the estimated plume arrival time, and also to describe situations where doses have already been received because actions could not be initiated in time.

One tab (Ingestion foodstuff selection) is dedicated to the specification of the foodstuffs to be considered. The following possibilities are offered:

- Inclusion in the criterion dose: this approach is suitable to describe ingestion components that cannot reasonably be avoided when people lead a normal life in the affected area. It is assumed that these are foodstuffs with legally permitted contamination levels ("marketable foodstuffs") with significant local production that is sold in shops and supermarkets and consumed by the local general population. 


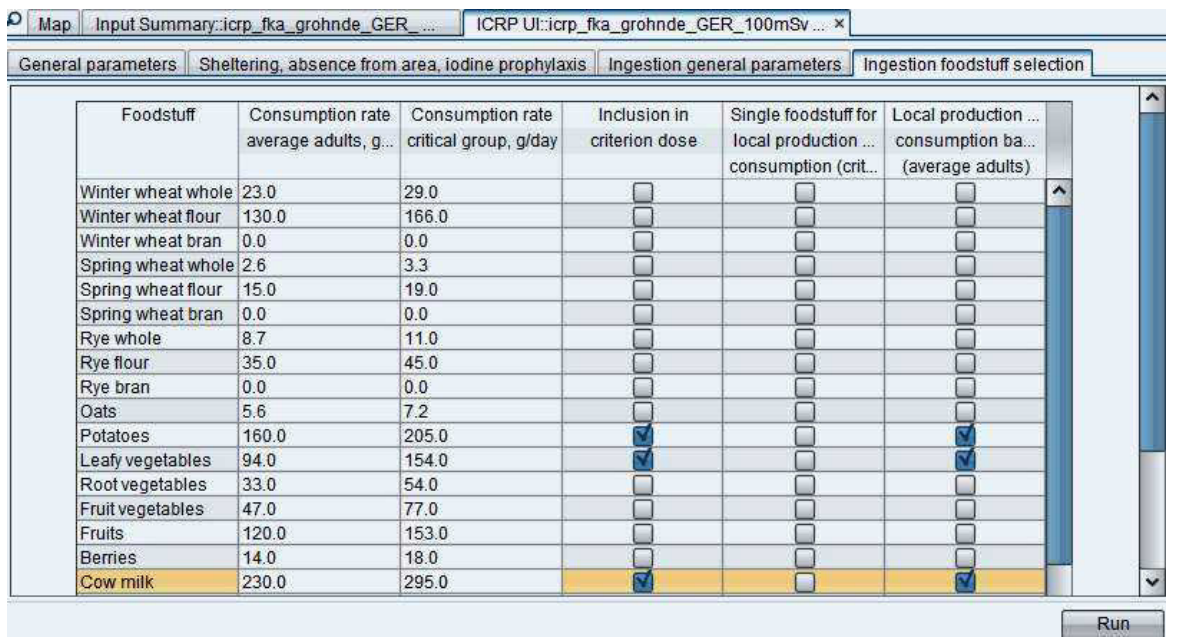

Figure 1. Tabbed panel of ICRP 1.0, with active "Ingestion foodstuff selection" tab and selection example (JRodos).

\begin{tabular}{|l|l|l|l|l|}
\hline \multicolumn{6}{|c|}{ Consider Food Intervention Levels (CFILs, Bq/kg) for ingestion doses } \\
\hline \multicolumn{1}{|c|}{ Radionuclide } & Milk produc.. & Other food & Minor food & Liquid food \\
\hline 131 I & 500 & 2000 & 2000 & 500 \\
\hline${ }^{137} \mathrm{Cs}$ & 1000 & 1000 & 1000 & 1000 \\
\hline${ }^{90} \mathrm{Sr}$ & 125 & 750 & 750 & 125 \\
\hline $\begin{array}{l}\text { Alpha emitting isotopes of } \\
\text { plutonium and } \\
\text { transplutonium elements }\end{array}$ & 20 & 80 & 80 & 20 \\
\hline
\end{tabular}

Figure 2. Tabbed panel of ICRP 1.0, with active "Ingestion general parameters" tab and default settings (JRodos, merge of two screen shots).

- Inclusion in an additional ingestion screening step: this approach can be used to investigate individual locally produced foodstuffs under the aspect of critical consumption rates, or the consumption of a special locally produced food basket with average consumption habits, e.g. by some self-suppliers; with this approach consumer groups can be considered that do not know or care about controlling their produce by selecting a respective option in a further tab (Ingestion general parameters).

After having terminated the input and started the respective application, the terrestrial food chain and dose module (FDMT) of JRodos executes first, in the background and without any user interaction, to generate information required in addition to that from the near-range local-scale model chain. Then the screening calculations are carried out.

\section{Example application with the ICRP 1.0 model}

\subsection{Scenario and input assumptions}

In the following, the screening model ICRP 1.0 is exemplified by means of an example accident scenario consisting of a source term from a recent probabilistic safety analysis study for German nuclear power plants (GRS, 2010) and recorded numerical weather prediction data for a time period in June
2012 from the German Weather Service. The hypothetical accident is assumed to take place at a German nuclear power plant. The source term describes a steam generator heating tube rupture with the leakage section not covered by water ${ }^{1}$. Significant releases begin 21 hours after reactor shutdown and continue for about 50 hours, with a total activity release in terms of fractions of the initial inventory of about $24 \%$ each of Xe-133 and Xe-135, and 10\% each of I-131 and Cs-137. The atmospheric dispersion and deposition calculations were carried out with the particle model Dipcot of JRodos for a time period of 96 hours following an assumed release beginning on June 3, 2012, at 03:00 coordinated universal time (UTC).

With the above scenario, an ICRP screening analysis was carried out to investigate the implications of a reduction of the 'open air' criterion dose below a reference level of $100 \mathrm{mSv}$. As a dose-mitigating action, only absence from the area was considered - the long delay between reactor shutdown and the first release combined with the apparent severity of the assumed in-plant scenario and the difficult weather situation makes sheltering unfavourable. In addition, thyroid blocking is not unproblematic for an iodine-deficient country such as Germany. Testing for the action efficiencies begins at time zero everywhere on the calculation grid - if absence is indicated, it is assumed to be initiated before plume arrival everywhere.

\footnotetext{
1 Source term category "FKA" in reference (GRS, 2010); "FK" stands for "Freisetzungskategorie", which means "Release category" in English.
} 


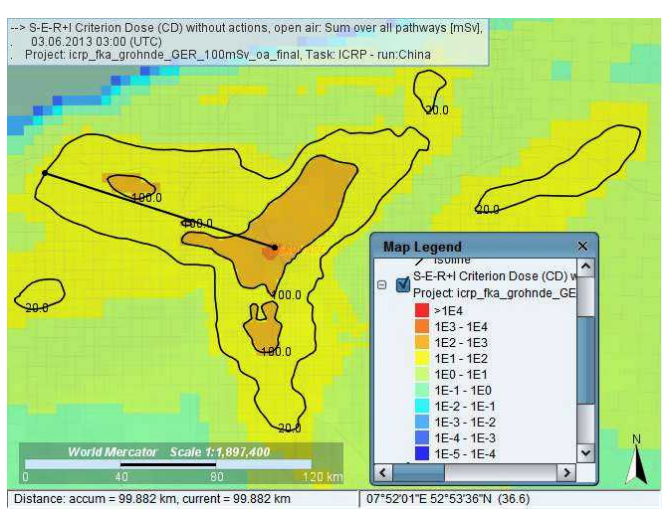

(a)

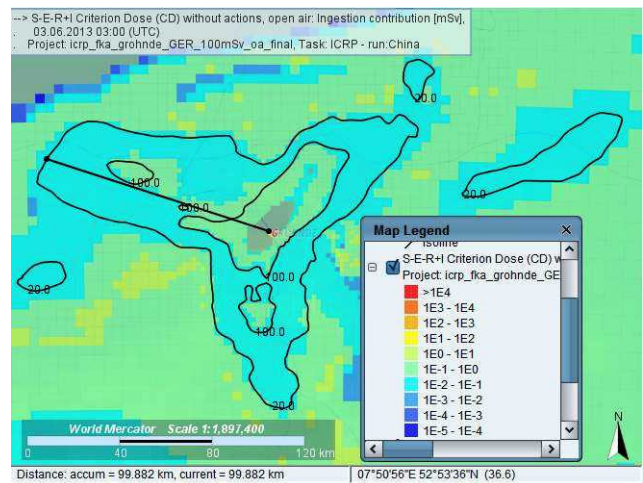

(b)

Figure 3. Example scenario, ICRP-1.0 (JRodos screenshots). $20 \mathrm{mSv}$ and $100 \mathrm{mSv}$ 'open air' criterion dose isolines indicated for (a) the no action criterion dose, and (b) the contribution of ingestion of the marketable local food basket.

The assumptions made with respect to the food situation in the analysed region are as follows. Locally produced leafy vegetables, potatoes and milk are an integral part of the local food basket for residents in the area. Therefore, the local food production will be monitored to guarantee compliance with allowed limits; if they do, they will be marketed. However, there are a few self-suppliers that may not agree with (or know the need for) having their produce controlled. The user inputs reflecting these assumptions are displayed in Figure 1, which also shows the default consumption rates that are contained in the JRodos region-specific database (here: for European average radio-ecological region No. 1). Figure 2 shows the default activity limits used in the assessment; they correspond to the EC maximum permitted levels of radioactive contamination of foodstuffs (Council Regulation, 1987, 1989).

\subsection{Steps in the calculation and basic results}

Each screening calculation starts with the assessment of areas with the possibility of severe deterministic effects, with threshold levels applied to whole-body and individual organ/tissue 'open air' doses received over a time span of two days. For scenarios lasting longer than two days, the test is repeated for each day until the end of the scenario, with two-day intervals covering the respective current day and the following day. All grid cells where any of the threshold levels is exceeded are recorded, together with the first day in the scenario for which this was the case.

Next, the effective equivalent dose in the first year from all terrestrial exposure pathways is determined. The non-ingestion contributions are calculated with 'open air' or 'normal living' exposure as selected by the user, without consideration of dose-reducing actions. The ingestion contributions are calculated under the assumption of local production and consumption with average consumption rates, always ensuring that the calculated activity levels in the user-selected foodstuffs do not exceed the user-defined limits. The sum of all the dose contributions is the "no action criterion dose", and a key quantity for the screening procedure.

Figure 3 a shows this "no action criterion dose" for the example scenario, calculated with the 'open air' exposure assumption. The weather situation during the atmospheric transport phase of the radioactive clouds in the region is complicated. Until about 10:00 UTC on June 3, 2012, there was a high-pressure zone with winds from easterly directions, and then a storm front with rain showers came, first with wind from westerly directions, then from variable directions. This results in the complicated contamination pattern observed. The $20 \mathrm{mSv}$ and $100 \mathrm{mSv}$ isoline is indicated, representing the recommended range for the reference level in an emergency situation. For $20 \mathrm{mSv}$, the isoline extends up to $100 \mathrm{~km}$ distance from the nuclear power plant, with disconnected patches ranging to about $160 \mathrm{~km}$. The $100 \mathrm{mSv}$ isoline extends to about $45 \mathrm{~km}$. Figure $3 \mathrm{~b}$ shows the ingestion contribution from the locally produced food basket with the EC maximum permitted levels assumed to be in operation; it is small, maximum $0.4 \mathrm{mSv}$, and generally much lower.

Then, a strategy for reducing the 1st year "no action criterion dose" below the reference level is identified by considering thyroid blocking, sheltering and evacuation/relocation in all grid cells where the calculated "no action criterion dose" exceeds the user-specified reference level. In each affected cell the testing begins at the location-dependent action sequence starting time that was specified by the user in the initialisation phase. The "lightest" action is tested first, then the next "heavier" one and so on, until there is no action option left. Exceptions are grid cells with a potential for severe deterministic health effects; there, only absence from the area is considered and the cells are characterised by an "Absence (det.effects)" tag.

The first analysed action is thyroid blocking, if selected. The inhalation dose contribution to the criterion dose is recalculated under the assumption of $100 \%$ efficiency; see (Landman et al., 2013). If that suffices to reduce the modified criterion dose below the reference level, the problem is considered to be solved and the cells are characterised by an "iodine tablets sufficient" tag. If not, the effect of sheltering only is analysed, if selected. The criterion dose is recalculated under the assumption that the people stay in buildings with windows closed and ventilation switched off, with shielding factors applied for external $\gamma$ exposure and inhalation from the JRodos region-specific database. During sheltering, the ingestion 


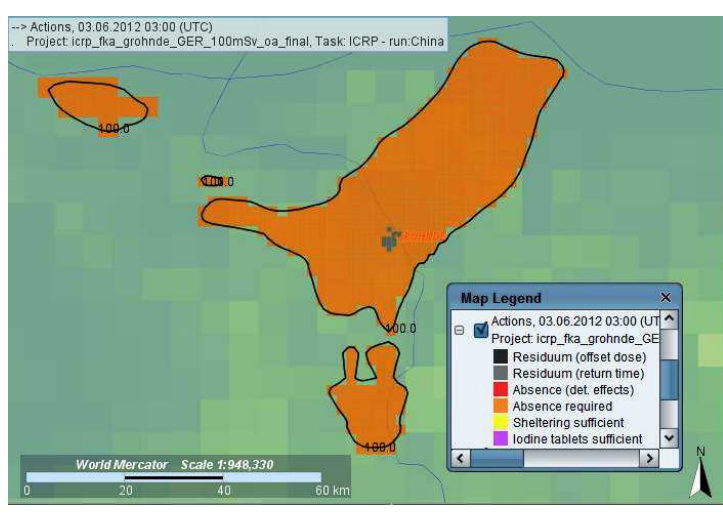

(a)

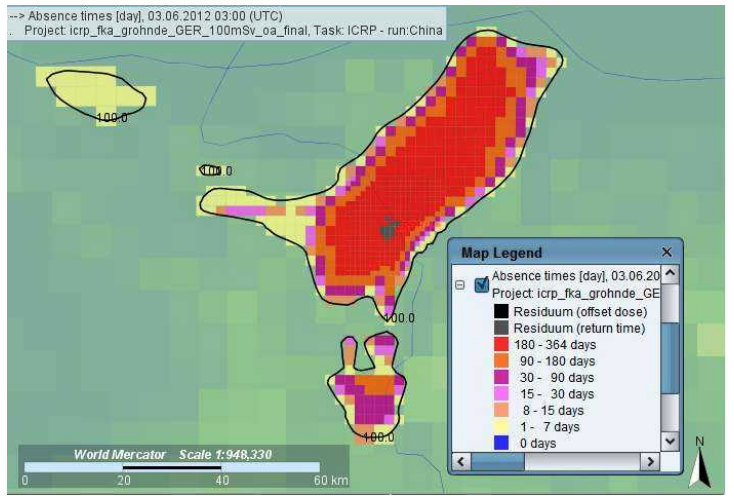

(b)

Figure 4. Example scenario, ICRP 1.0 (JRodos screenshots) with $100 \mathrm{mSv}$ 'open air' no action criterion dose isoline for (a) the action pattern and (b) minimum absence times.

of marketable foodstuffs is assumed to be interrupted. If this suffices to reduce the modified criterion dose below the reference level, the problem is considered to be solved and the cells are characterised by a "sheltering sufficient" tag. If not, removing the people from the area is considered, optionally preceded by a sheltering period. For this, the 1 st year criterion dose is recalculated for different "end of absence" times until the end of the first year (initially 'days', later 'weeks', and finally 'months'), under the assumption that all exposure pathways including ingestion are interrupted during absence and resumed after return. The ingestion dose component can exhibit a complicated time pattern with repeated increase and decrease, dependent on the foodstuff, date of accident, nuclide composition and food ban assumption. When included in the criterion dose, the latter can fall repeatedly below the reference level and then exceed it again as time goes on. If an absence time is found for which the modified criterion dose drops below the reference level and does not exceed it again in future, the problem is considered to be solved. Such cells are characterised by an "absence required" tag, and the lowest absence time for which this condition is valid is recorded. If no such solution can be found within the first twelve months (or a userspecified lower time), the respective grid cell gets a 'residuum (return time)' tag. This tag indicates the necessity for other actions; suitable ones could be determined, for instance, with the European Model for Inhabited Areas, ERMIN.

The main result of the assessment is the flag pattern indicating the actions that suffice to bring the 1st year "modified criterion dose" below the reference level together with the associated "absence times". With respect to the latter, thyroid blocking and sheltering require no absence (absence time is zero). Figure 4 displays such an action pattern (Figure 4a) and the respective absence times (Figure 4b) for the example scenario. Also indicated is the $100 \mathrm{mSv}$ isoline that was used to define the area of interest for this analysis. Because sheltering and iodine prophylaxis was not considered, Figure 4a contains only entries for 'absence required' and 'residuum (return time)'. Figure $4 \mathrm{~b}$ shows that outside the residuum area the minimum absence times range from about a week in the fringes to several months in the inner parts. For the more highly contaminated areas, one could use ERMIN to find out if it is possible to decontaminate so that the absence period could be reduced to 3 to 6 months.

Figure 5 shows for the example scenario the 1st year criterion dose calculated under the assumption that the action pattern from Figure $4 \mathrm{a}$ was carried out. Inside the area of interest all doses lie below the chosen reference level (here: $100 \mathrm{mSv}$ ) except in areas with a 'residuum' tag, where no considered action could achieve the goal. Outside the area of interest, the dose is simply the "no action criterion dose" from Figure 1a. For large parts of the area of interest, the modified criterion dose values lie rather close to the assumed reference level. This is due to the fact that in the current model the end of absence is defined by the value of the reference level and not by some lower value.

The assessments described so far concerned the general population. In an additional ingestion screening step, ICRP 1.0 can be used to investigate the implications of special cases; for instance, the consumption of a local food basket without control of the contamination levels. For such analyses the model recalculates the ingestion components of the "lightest action set" criterion dose and compares the newly modified criterion dose once again with the reference level. If it is exceeded, it is checked how long the respective ingestion pathways must be interrupted to achieve the goal, using the same test times as before. If the test fails for the last considered test time, the corresponding grid cells are tagged with a 'Residuum ING' flag. This analysis is carried out for the whole calculation grid, except for residuum cells from the previous sheltering, evacuation and relocation screening step; in the results from the ingestion step, they are identified by the label 'Residuum SER'.

For the example scenario, Figure 6a shows the recalculated ingestion dose component, here assuming the "lightest action set" together with the consumption of an uncontrolled local food basket, and Figure $6 \mathrm{~b}$ shows the calculated end of the corresponding ingestion problem. The time pattern is complicated, because it is the result of a combination of the absence times from the "lightest action set" during which the ingestion pathways are considered as interrupted, and the time dependence of the foodstuff contamination, in the example application for three foodstuffs. Any 'Residuum ING' tag indicates the necessity for other actions; suitable ones could be 


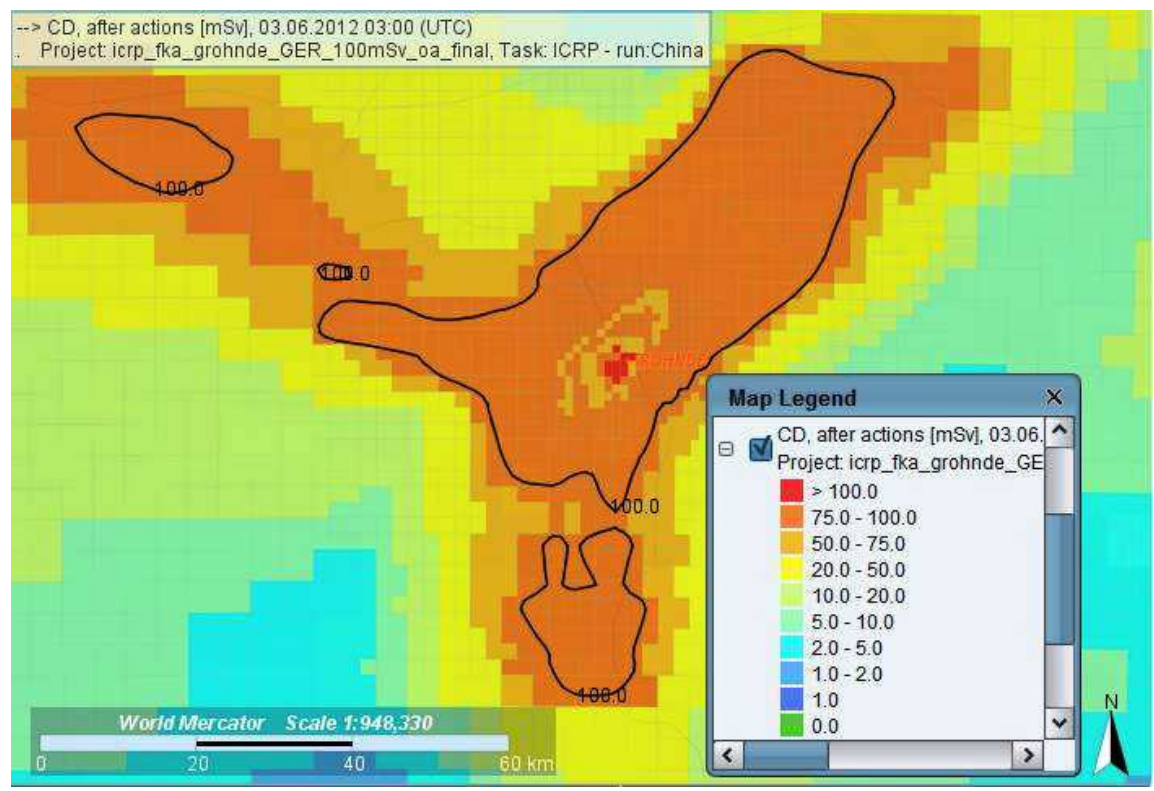

Figure 5. Criterion dose modified by the assumption that the "lightest action set" is applied; with $100 \mathrm{mSv}$ 'open air' no action criterion dose isoline. Example scenario, ICRP-1.0 (JRodos screenshots).

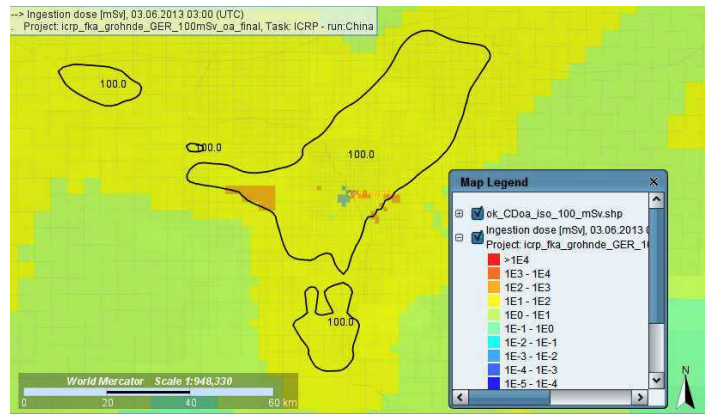

(a)

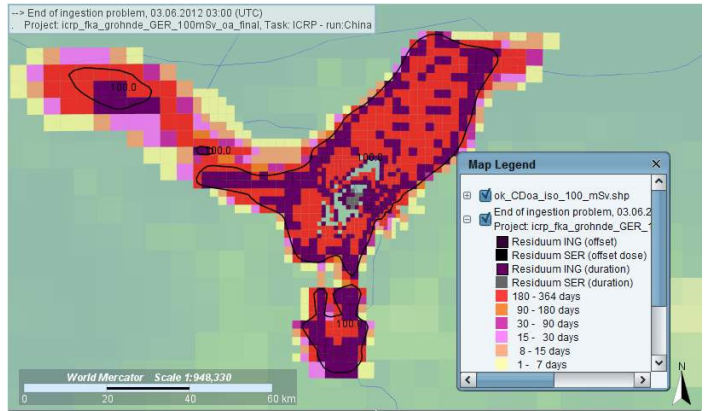

(b)

Figure 6. Example scenario, ICRP-1.0 (JRodos screenshots) with $100 \mathrm{mSv}$ 'open air' no action criterion dose isoline for (a) the effective equivalent dose from ingestion of an uncontrolled local food basket and (b) the predicted end of the corresponding ingestion problem.

determined, for instance, with the Agricultural Countermeasure Program, AgriCP.

\section{Conclusions}

The JRodos screening tool identifies one particular action strategy that can keep the residual dose in the 1st year below the reference level, for the general population as well as for critical subgroups with respect to food consumption. The identified areas and absence times can also serve as a guideline for optimising the longer-term exposure situation; for example, with the European Model for Inhabited Areas, ERMIN, and the Agricultural Countermeasure Program, AgriCP. Apart from the primary results, supportive results are available that allow in-depth analysis of the screening assessment.

The chosen approach is consistent in the sense that the combined effect of actions is considered under the one constraint of keeping a criterion dose below a given numerical value. However, this is done only for the emergency situation in the 1st year, without consideration of controlling the existing exposure situation afterwards. Also, the question if sheltering, evacuation and relocation, when imposed on the basis of national intervention levels, is sufficient to guarantee that the criterion dose in the first year will not be exceeded is currently not addressed. Model extensions regarding both aspects are under consideration.

\section{References}

Council Regulation - Euratom (1987) No 3954/87 of 22/12/1987 laying down maximum permitted levels of radioactive contamination of foodststuffs and of feedingstuffs following a nuclear accident or any other case of radiological emergency, Official Journal of the European Communities L146 of 30/12/1987, Luxembourg.

Council Regulation - Euratom (1989) No 2218/89 of 18/7/1989 amending Regulation (Euratom) No 3954/87 laying down maximum permitted levels of radioactive contamination of foodstuffs and of feedingstuffs following a nuclear accident or any other 
case of radiological emergency, Official Journal of the European Communities L211 of 22/7/1989.

GRS (2010) Aktualisierung der Quelltermbibliothek des Entscheidungshilfesystems RODOS für Ereignisse im Leistungsbetrieb, Abschlussbericht zum Vorhaben 3609S60009, GRS, Okt. 2010.

ICRP Publication 103 (2007) The 2007 recommendations of the International Commission on Radiological Protection, Ann. ICRP 37, Elsevier.
Ievdin I., Trybushnyi D., Zheleznyak M., Raskob W. (2010) RODOS reengineering: aims and implementation details, in: Enhancing nuclear and radiological emergency management and rehabilitation: Key results of the EURANOS European project (W. Raskob, M. Hugon, Eds.), Radioprotection 45 (5), S181-S189.

Landman C., Päsler-Sauer J., Raskob W., Trybushnyi D. (2013) A proposed countermeasure simulation model for the new ICRP recommendations (T. Duranova, W. Raskob, R. Mustonen, T. Schneider, Eds.), Radioprotection 48 (5), S49-S56.

Cite this article as: C. Landman, W. Raskob, D. Trybushnyi, I. Ievdin. An application example for the new ICRP screening tool of JRodos. Radioprotection 51(HS1), S17-S22 (2016). 